\title{
REQUESTED COMMENT CONCERNING: LIDOFLAZINE
}

\author{
Willem Flameng, MD, Leuven, Belgium
}

Lidoflazine is a drug that was developed by the Janssen Research Laboratories (Janssen Pharmaceutics, Beerse, Belgium) several decades ago but never became available on the international market. It has strong nucleoside transport inhibitory properties and can be classified as an ARA or adenosine regulating agent. ${ }^{1}$ Recently, there has been increasing interest in this type of drugs for myocardial protection, because they all enhance the tissue content of adenosine in the myocardium. Adenosine is widely known for its cardioprotective properties against ischemic damage. ${ }^{2}$ Accumulation of adenosine in the myocardium can be obtained by prevention of its breakdown (for example, by inhibition of its transport from the myocyte to the endothelial cell where adenosine is catabolized) or by stimulating its production. The latter can be done by infusing the precursor AICA riboside (5-amino-4-imidazole carboxamide riboside). This drug is now under clinical investigation in large multicenter studies in the United States, Canada, and Europe.

The study of Akpinar, Vanerman, and Wellens is interesting in so far as it demonstrates that extensive coronary bypass grafting can safely be done on the fibrillating heart using one single period of aortic crossclamping combined with lidoflazine pretreatment. The clinical outcome was the same as when cardioplegia was used. However, the study does not provide scientific proof

From the Department of Cardiac Surgery, Katholieke Universiteit Leuven, Herestraat 49, B-3000 Leuven, Belgium.

J Thorac Cardiovasc Surg 1995;109:1015

Copyright (C) 1995 by Mosby-Year Book, Inc.

0022-5223/95 $\$ 3.00+0 \quad \mathbf{1 2 / 8 / 5 9 9 5 6}$ for the cardioprotective properties of lidoflazine because the study was not placebo controlled. I realize, however, that a placebo-controlled study is unethical because prolonged uninterrupted periods of ischemia, mainly on the fibrillating heart, will cause considerable myocardial damage. ${ }^{3}$ The lack of significant release of creatine kinase-MB as reported by Akpinar's group and the excellent clinical outcome suggest that myocardial injury is virtually absent in this setting. Although there is experimental evidence that lidoflazine will prevent myocardial damage even after 1 hour of normothermic global myocardial ischemia, ${ }^{4}$ these data cannot be extrapolated as such to the clinical situation and the diseased human heart. Therefore, I believe that the technique described by Akpinar's group should not be advocated as generally applicable. Fast and skillful surgeons can use this technique, but they should realize that they might be balancing on a slack rope.

\section{REFERENCES}

1. Engler RL, Gruber HE. Adenosine: an autacoid. In: Fozzard HA, Haber E, Jennings RB, et al., eds. The heart and cardiovascular system. New York: Raven Press, 1992:1745-64.

2. Belardinelli I, Linden J, Berne RM. The cardiac effects of adenosine. Prog Cardiovasc Dis 1989;32:73-97.

3. Reimer KA, Lowe JE, Rasmussen MM, Jennings RB. The wave-front phenomenon of ischemic cell death. Circulation 1977;56:786-91.

4. Flameng W, Daenen W, Borgers M, et al. Cardioprotective effects of lidoflazine during 1 hour normothermic global ischemia. Circulation 1981;64:796-807.

\section{FIRST CLINICAL USE OF A HEPARIN REMOVAL DEVICE: AN ALTERNATIVE TO PROTAMINE}

\author{
Vincent R. Conti, MD, Roger A. Vertrees, BA, CCP, Joseph B. Zwischenberger, MD, and Mark Kurusz, CCP, \\ Galveston, Tex.
}

The reversal of heparin with protamine sulfate after termination of cardiopulmonary bypass (CPB) can elicit severe life-threatening reactions. These reactions can

From the Division of Cardiothoracic Surgery, The University of Texas Medical Branch, Galveston, Tex.

J Thorac Cardiovasc Surg 1995;109:1015-7

Copyright (C) 1995 by Mosby-Year Book, Inc.

$0022-5223 / 95 \$ 3.00+0 \quad \mathbf{1 2 / 8 / 5 8 2 0 7}$ occur despite such precautions as using a test dose of protamine, slow injection into the arterial side of the circulation, and premedication with steroids or $\mathrm{H}-1 / \mathrm{H}-2$ blockers. The adverse reactions occur more frequently in patients previously exposed to protamine, such as patients having second cardiac operations, patients with diabetes who receive neutral protamine Hagedorn (NPH) insulin, and patients with preoperative pulmonary hypertension. As an alternative to protamine administration, the Heparin Removal Device was developed by Research 


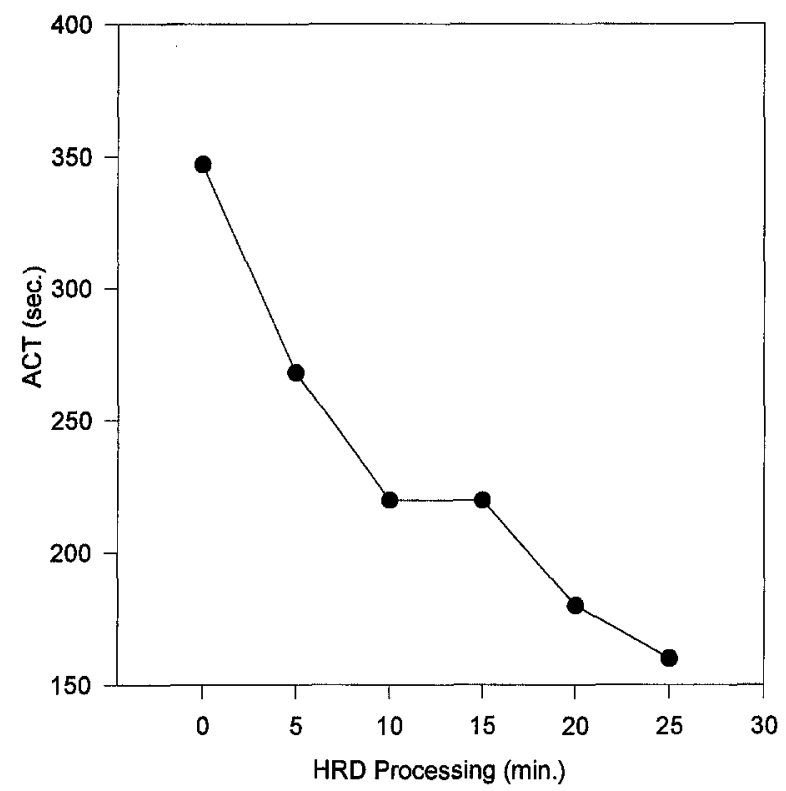

Fig. 1. Time course for ACT during the Heparin Removal Device $(H R D)$ processing period.

Medical, Inc., Midvale, Utah. The device is a commonly used extracorporeal plasmapheresis filter containing a special resin that binds and immobilizes heparin from circulating heparinized blood. In a pig model of $\mathrm{CPB}$ this device returned the activated clotting time (ACT) to baseline values from fully heparinized levels in approximately 20 minutes without any apparent adverse effects on other measured coagulation variables. ${ }^{1}$ We report the first clinical use of this device for lifethreatening bleeding in a patient who could not receive protamine. The Heparin Removal Device is still awaiting Food and Drug Administration (FDA) approval for clinical evaluation.

A 44-year-old woman with diabetes was admitted to The University of Texas Medical Branch Hospital because of progressive angina pectoris with recent episodes of angina at rest. She had diabetes since the age of 18 years. Her insulin regimen included 50 units of NPH insulin and 5 units of regular insulin a day. She had end-stage renal disease and had been undergoing hemodialysis for the past 2 years. Other problems included severe peripheral vascular disease necessitating amputation of the right forearm below the elbow 1 year before admission after a failed polytetrafluoroethylene graft for dialysis access.

Attempts at stabilization of the angina pectoris with medical therapy were not successful and she underwent cardiac catheterization, which showed severe three-vessel coronary artery disease. On November 30, 1993, she underwent coronary artery bypass grafting to four distal vessels, which included a free left internal mammary artery graft to the left anterior descending coronary artery. At operation, the patient was found to have severe diffuse coronary artery disease with marked calcification of all of the coronary arteries including the areas of anastomosis on two of the vessels. After revascularization, she had good hemodynamics and was weaned from CPB with a cardiac index of $3.1 \mathrm{~L} / \mathrm{min}$ per square meter and a blood pressure of $130 / 60 \mathrm{~mm} \mathrm{Hg}$. A test dose of protamine sulfate was administered into the left atrial line, after which she promptly had a severe reaction manifested by pulmonary vasospasm and systemic hypotension. The pulmonary artery pressure increased to $52 \mathrm{~mm} \mathrm{Hg}$ systolic followed by acute right heart failure, a marked fall in the left atrial pressure to less than 5 $\mathrm{mm} \mathrm{Hg}$, and a drop in systemic blood pressure to below $40 \mathrm{~mm} \mathrm{Hg}$ systolic. She required brief open cardiac massage and epinephrine administration before the hemodynamics were restored to a satisfactory state approximately 5 minutes later. Although the Heparin Removal Device was available, we realized it was not approved even as an investigational device, and we attempted conventional therapy. Additional protamine was withheld, hemostasis was obtained, and the chest was closed with what was believed to be minimal bleeding considering her fully anticoagulated state. The ACT was 459 seconds before she was transferred from the operating room.

By the time she had arrived in the intensive care unit, brisk bleeding had begun, with chest tube drainage of $2400 \mathrm{ml}$ in the first hour after arrival. In addition to her heparinized state (ACT of 427 seconds), she also had a significant coagulopathy with evidence of fibrinolysis. The partial thromboplastin time was more than 150 seconds, prothrombin time 48 seconds, fibrinogen level $209 \mathrm{gm} / \mathrm{dl}$, fibrin degradation products greater than 20 $\mu \mathrm{g} / \mathrm{ml}$, and platelet count $130,000 \mu \mathrm{l}$. She was returned to the operating room, the sternotomy was opened, and the mediastinum reexplored. No significant specific bleeding sites were found, but hemostasis was still inadequate and bleeding continued. The combination of her heparinized state and severe coagulopathy, in the presence of end-stage renal failure, made it unlikely that the bleeding could be controlled without massive use of blood bank resources and placing her at great risk. We therefore decided to use the Heparin Removal Device. After obtaining verbal approval for compassionate one-time use of this FDA unapproved device from the chairman of our institutional review board, we implemented the procedure. The dual-flow venovenous cannula was inserted through the atriotomy and was attached to a heparin-coated extracorporeal circuit that removes blood from the inferior vena cava by a roller pump. That then propels the blood forward through the plasma separator and subsequently back to the other arm of the venovenous cannula. Within the curesis device, hollow fibers allow for plasmapheresis to occur. The heparinized and separated plasma comes into contact with the Heparin Removal Device sorbent material, which then absorbs the heparin and immobilizes it by means of a poly-L-lysine ligand. The plasma then spontaneously reenters the blood pathway as the blood circulates through the curesis device and returns to the right atrium through the proximal port of the double-lumen catheter.

The Heparin Removal Device was used with a circulation rate of $500 \mathrm{ml} / \mathrm{min}$ for 25 minutes. Fig. 1 shows the 
time course of the ACT over this period of heparin removal. The ACT after completion of this treatment was 160 seconds, whereas the baseline ACT before CPB was 192 seconds. Other coagulation studies, however, showed a persistent coagulopathy that was corrected over the next 4 hours with infusion of fresh frozen plasma and cryoprecipitate. She was also treated with epsilon aminocaproic acid to correct abnormal fibrinolysis. The chest tube output was 300 to $400 \mathrm{ml} / \mathrm{hr}$ for the first 4 hours after heparin removal but diminished to an insignificant level, and she did well thereafter.

No alternatives to protamine for heparin reversal are currently available. Although platelet factor 4 has been shown to be an effective neutralizer of heparin, ${ }^{2}$ it is in the early stages of investigation and will likely not be available in the near future. The Heparin Removal Device uses a plasmapheresis filter that is widely used clinically but has a resin added to the plasma compartment that binds and removes heparin. This approach to heparin removal has great potential merit as an alternative to protamine. It awaits a phase 1 clinical trial after FDA review and approval as an investigational device.

\section{REFERENCES}

1. Vertrees RA, Zwischenberger JB, McRea JC, Kurusz M, Conti VR. Reversal of anticoagulation without protamine. ASAIO J 1994;40:M560-4.

2. Bernabei AF, Gikakis N, Malone TE, Niewiarowski $\mathrm{S}$, Edmunds LH. Platelet factor 4-an alternative to protamine. J Thorac CARdiovasc Surg [In press].

\section{PRELIMINARY RESULTS OF DEFEROXAMINE AND L1 TREATMENT OF SPINAL CORD ISCHEMIA}

David G. Reuter, PhD, MD, Willis A. Tacker, Jr., MD, PhD, Charles F. Babbs, MD, PhD, Stephen F. Badylak, DVM, PhD, MD, William D. Voorhees III, PhD, and Peter E. Konrad, PhD, MD, West Lafayette, Ind.

Vascular surgery necessitating aortic occlusion produces spinal cord ischemia, which can subsequently lead to paraplegia. Previous studies suggest lipid-rich central nervous system tissue is sensitive to amplification of ischemic injury by free radical mechanisms that lead to lipid peroxidation. ${ }^{1}$ Drugs that prevent free radical production and thus lipid peroxidation offer promise as a way to protect the spinal cord during periods of ischemia. ${ }^{2}$ The agents deferoxamine and 1,2-dimethyl-3-hydroxypyrid-4one (L1) are postulated to inhibit iron-catalyzed lipid peroxidation. Deferoxamine is a water-soluble iron chelator that has been shown to attenuate reperfusion injury in isolated rat hearts. ${ }^{3} \mathrm{~L} 1$ is a novel lipid-soluble iron chelator that has been shown to effectively chelate excess iron in a study of chronic transfusional iron overload (i.e., $\beta$-thalassaemia). ${ }^{4}$ Our goal was to use these two drugs to test the hypothesis that iron plays an important role in the pathophysiologic reactions leading to spinal cord damage attendant to ischemia and reperfusion.

Our preliminary study was performed in two stages. We

From the Hillenbrand Biomedical Engineering Center, Purdue University, West Lafayette, IN 47907-1293.

Supported by grant HL-36712 from the National Heart, Lung, and Blood Institute, U.S. Public Health Service, Bethesda Md.

J Thorac Cardiovasc Surg 1995;109:1017-9

Copyright (C) 1995 by Mosby-Year Book, Inc.

$0022-5223 / 95 \$ 3.00+0 \quad \mathbf{1 2 / 8 / 5 8 6 0 9}$ first developed a model of spinal cord ischemia that produced paraplegia in a majority of dogs..$^{5}$ The second phase of our study used the initial series of dogs as historical controls to determine if treatment with deferoxamine or L1 would significantly improve the neurologic outcome or histopathologic damage.

In the second phase of our study, 13 mongrel dogs were sequentially divided into a deferoxamine-treated group $(n=5)$ and an L1 group $(n=8)$. The dogs were pretreated with atropine sulfate $0.4 \mathrm{mg} / \mathrm{kg}$ subcutaneously and acetylpromazine $0.22 \mathrm{mg} / \mathrm{kg}$ subcutaneously and were anesthetized with thiopental 9 to $13 \mathrm{mg} / \mathrm{kg}$ intravenously. After intubation, nitrous oxide was delivered by inhalation in a 1:2 ratio with oxygen, and anesthesia was maintained by repeated intravenous boluses of thiopental. A balloon catheter was inflated in the aorta just distal to the left subclavian artery to achieve spinal cord ischemia, and the duration of ischemia was determined by the amplitude reduction of the mean evoked potential signal, as it was in our initial study. The details of the evoked potential stimulaton, histopathologic scoring, regional blood flow studies, and neurologic assessment are identical to phase 1 of the study. ${ }^{5}$ In the first group of dogs, deferoxamine 25 $\mathrm{mg} / \mathrm{kg}$ was infused intravenously over a 20 -minute period, starting 30 minutes before aortic occlusion. Another 25 $\mathrm{mg} / \mathrm{kg}$ dose of deferoxamine was administered over a 20 -minute period beginning 10 minutes before reperfusion. In the other group, L1 $25 \mathrm{mg} / \mathrm{kg}$ was administered intravenously according to the same protocol. All animals received humane care in compliance with the "Principles 